\title{
Some Results Related to the Lattice of Fuzzy Topologies on a Fixed Set
}

\author{
Baby Chacko \\ Associate Professor, Department of Mathematics, St.Joseph's College, Devagiri, Calicut-8, Kerala, India.
}

\begin{abstract}
The set of all $L$ - fuzzy topologies on a fixed set $X$ is a complete lattice denoted by LFT(X,L). In this paper, we determine some classes of automorphisms of this lattice when $X$ is a nonempty set and $L$ is an Flattice.
\end{abstract}

Mathematics Subject Classification: $54 A 40$

Keywords: fuzzy topological space, lattice automorphism, t- homomorphism, pseudo-complement, F-lattice, order reversing involution.

\section{Introduction}

In 1958, Juris Hartmanis [2] determined the automorphisms of the lattice LT(X) of all topologies on a fixed set $X$ as follows : for $p \in S(X)$ and $\tau \in L T(X)$, define the mapping $A_{p}$ by $A_{p}(\tau)=\{p(U): U \in \tau\}$. Then $A_{p}(\tau)$ is a topology on $X$ and $A_{p}$ is an automorphism of $L T(X)$. If $X$ is infinite or $X$ contains atmost two elements, the set of all automorphisms of $\operatorname{LT}(X)$ is precisely $\left\{A_{p}: p \in S(X)\right\}$. Otherwise, the set of all automorphisms of $\mathrm{LT}(X)$ is $\left\{\mathrm{A}_{\mathrm{p}}: \mathrm{p} \in \mathrm{S}(\mathrm{X})\right\} \cup\left\{\mathrm{B}_{\mathrm{p}}: \mathrm{p} \in \mathrm{S}(\mathrm{X})\right\}$ where $\mathrm{B}_{\mathrm{p}}: \mathrm{LT}(X) \rightarrow \mathrm{LT}(X)$ is defined by $\mathrm{B}_{\mathrm{p}}(\tau)$ $=\{X-p(U): U \in \tau\}$ for $\tau \in L T(X)$. From this result, we can conclude that, if $X$ is an infinite set and $P$ is any topological property, then the set of topologies in LT (X) possessing the property P may be identified simply from the lattice structure of $\mathrm{LT}(\mathrm{X})$, since the only automorphisms of $\mathrm{LT}(\mathrm{X})$ for infinite $\mathrm{X}$ are those which simply permute elements of X. Therefore any automorphism of LT(X) must map all the topologies in LT(X) onto their homeomorphic images. Thus the topological properties of elements of $\mathrm{LT}(\mathrm{X})$ must be determined by the position of the topologies in $\mathrm{LT}(\mathrm{X})$. In this paper, we determine some classes of automorphisms of lattice $\operatorname{LFT}(\mathrm{X}, \mathrm{L})$ where $\mathrm{L}$ is a complete, distributive and pseudo complemented lattice (or an F - lattice).

\section{Preliminaries}

Let $\mathrm{X}$ be any nonempty set and $\mathrm{L}$ be a complete and distributive lattice.

\section{Definition. 1}

Let $\mathrm{X}$ be a nonempty set, $\mathrm{L}$ a complete lattice. An L-fuzzy subset $\mathrm{A}$ of $\mathrm{X}$ is a mapping $\mathrm{A}: \mathrm{X} \rightarrow \mathrm{L}$. The family of all L-fuzzy subsets of $\mathrm{X}$ is denoted by $\mathrm{L}^{\mathrm{X}}$. For brevity, we call an L-fuzzy subset of $\mathrm{X}$ as a fuzzy subset of X.

Definition. 2

Define the partial order $\leq$ in $\mathrm{L}^{\mathrm{X}}$ by : For all $\mathrm{A}, \mathrm{B} \in \mathrm{L}^{\mathrm{X}}$, $\mathrm{A} \leq \mathrm{B} \Leftrightarrow \mathrm{A}(\mathrm{x}) \leq \mathrm{B}(\mathrm{x})$ for all $\mathrm{x} \in \mathrm{X}$. With this partial order, $\mathrm{L}^{\mathrm{X}}$ is a complete lattice. The smallest and the greatest elements of $\left(\mathrm{L}^{\mathrm{X}}, \leq\right)$ are the constant functions taking the values 0 and 1 respectively and are denoted by $\underline{0}$ and $\underline{1}$.

Definition. 3

Let $\mathrm{L}$ be a lattice. A mapping ' $: \mathrm{L} \rightarrow \mathrm{L}$ is called order-reversing if, for all $\mathrm{a}, \mathrm{b} \in \mathrm{L}, \mathrm{a} \leq \mathrm{b} \Rightarrow \mathrm{a}^{\prime} \geq \mathrm{b}^{\prime}$; called an involution on $\mathrm{L}$ if, $\mathrm{a} "=\mathrm{a}$ for all $\mathrm{a} \in \mathrm{L}$. It is obvious that an involution is always a bijection.

Definition. 4

A complete and distributive lattice $\mathrm{L}$ is called an $\mathrm{F}$ - lattice, if $\mathrm{L}$ has an order reversing involution ' : $\mathrm{L} \rightarrow \mathrm{L}$. Let $\mathrm{X}$ be a non-empty ordinary set, $\mathrm{L}$ an F- lattice, ' the order reversing involution on $\mathrm{L}$. For all $\mathrm{A} \in \mathrm{L}^{\mathrm{X}}$ use the order reversing involution ' on $\mathrm{L}^{\mathrm{X}}$ by $\mathrm{A}^{\prime}(\mathrm{x})=(\mathrm{A}(\mathrm{x}))^{\prime}$ ' for all $\mathrm{x} \in \mathrm{X}$. Call ' $: \mathrm{L}^{\mathrm{X}} \rightarrow \mathrm{L}^{\mathrm{X}}$ the pseudocomplementary operation on $\mathrm{L}^{\mathrm{X}}, \mathrm{A}^{\prime}$ the pseudo-complementary set of $\mathrm{A}$, (or the pseudo-complement of $\mathrm{A}$ ) in $\mathrm{L}^{\mathrm{X}}$.

Lemma : 1

Let $\mathrm{X}$ a nonempty ordinary set, $\mathrm{L}$ an F-lattice, then the pseudo-complementary operation ' $: \mathrm{L}^{\mathrm{X}} \rightarrow \mathrm{L}^{\mathrm{X}}$ is an order reversing involution.

Definition. 5

Let $\mathrm{X}$ be a nonempty ordinary set, $\mathrm{L}$ an $\mathrm{F}$ - lattice, $\delta \subseteq \mathrm{L}^{\mathrm{X}}$. Then $\delta$ is called a fuzzy topology on $\mathrm{X}$ and $(\mathrm{X}, \delta)$ or $\left(\mathrm{L}^{\mathrm{X}}, \delta\right)$ is called a fuzzy topological space, if $\delta$ satisfies the following three conditions :

(i) $\underline{0}, \underline{1} \in \delta$

(ii) $\quad$ For all $\mathrm{A} \subseteq \delta, \vee \mathrm{A} \in \delta$. 
(iii) For all $\mathrm{A}, \mathrm{B} \in \delta, \mathrm{A} \wedge \mathrm{B} \in \delta$.

Definition. 6 set in $\mathrm{L}^{\mathrm{X}}$

An element of $\delta$ is called an open set in $\mathrm{L}^{\mathrm{X}}$. A pseudo-complement of an open set is called a closed

Definition. 7

Let $\mathrm{X}$ be a nonempty set and $\delta_{1}, \delta_{2}$ be two fuzzy topologies on X. We say $\delta_{1}$ is " coarser than " $\delta_{2}$ (or $\delta_{2}$ is finer than $\delta_{1}$ ) if $\delta_{1} \leq \delta_{2}$.

\section{Remark. 1}

The relation " coarser than " denoted by $\leq$ is a partial order relation on the set of all fuzzy topologies on $\mathrm{X}$. The set of all fuzzy topologies on X denoted by LFT(X,L) is a complete lattice under the relation $\leq$ defined above. The smallest element of $\operatorname{LFT}(\mathrm{X}, \mathrm{L})$ is the indiscrete fuzzy topology $\delta=\{\underline{0}, \underline{1}\}$ and the greatest element is the discrete fuzzy topology $\delta=\mathrm{L}^{\mathrm{X}}$.

Definition. 8 [1]

A t-homomorphism from a lattice $\mathrm{L}$ into a lattice $\mathrm{M}$ is a function $\mathrm{f}: \mathrm{L} \rightarrow \mathrm{M}$ such that

(i) $\mathrm{h}$ is a homomorphism

(ii) $\mathrm{h}(\underline{0)}=\underline{0}$ and $\mathrm{h}(\underline{1})=\underline{1}$

(iii) $\mathrm{h}\left(\vee \mathrm{k}_{\mathrm{i}}\right)=\vee \mathrm{h}\left(\mathrm{k}_{\mathrm{i}}\right)$ where $\left\{\mathrm{k}_{\mathrm{i}}: \mathrm{i} \in \mathrm{I}\right\}$ is an arbitrary subset of $\mathrm{L}$.

Remark. 2

Obviously every t-homomorphism is a homomorphism. But the converse need not be true.

\section{Main Results}

Let $\mathrm{X}$ be any non-empty set and $\mathrm{L}$ be an F- lattice. Let $\mathrm{p}: \mathrm{X} \rightarrow \mathrm{X}$ be a bijection and $\mathrm{g}: \mathrm{L} \rightarrow \mathrm{L}$ be a $\mathrm{t}-$ homomorphism. For $\mathrm{c} \in \mathrm{L}^{\mathrm{X}}$, define $\mathrm{H}_{\mathrm{p}, \mathrm{g}}$ by $\mathrm{H}_{\mathrm{p}, \mathrm{g}}(\mathrm{c})(\mathrm{x})=\mathrm{g}\left(\mathrm{c}\left(\mathrm{p}^{-\mathrm{I}}(\mathrm{x})\right)\right) ; \mathrm{c} \in \mathrm{L}^{\mathrm{X}}, \mathrm{x} \in \mathrm{X}$.

\section{Lemma. 1}

$\mathrm{H}_{\mathrm{p}, \mathrm{g}}$ is a bijection.

Proof:

Suppose $c, d \in L^{X}$ such that $H_{p, g}(c)=H_{p, g}(d)$. This implies that for each $x \in X, H_{p, g}(c)(x)=H_{p, g}$ $(d)(x) \Rightarrow g\left(c\left(p^{-1}(x)\right)\right)=g\left(d\left(p^{-1}(x)\right)\right)$. Since $g$ is one to one, this implies $c\left(p^{-1}(x)\right)=d\left(p^{-1}(x)\right)$. Since $p$ is a bijection this implies $c=d$. Hence $H_{p, g}$ is one to one. Let $a \in L^{X}$. Since $g$ is onto, for all $x \in X, g$ ${ }^{-I}(a(x))$ exists. Define $d: X \rightarrow L$ as follows : For $y \in X, d(y)=g^{-1}(a(p(y)))$. Clearly $d \in L^{X}$. For, $x \in$ $\mathrm{X}, \mathrm{H}_{\mathrm{p}, \mathrm{g}}(\mathrm{d})(\mathrm{x})=\mathrm{g}\left(\mathrm{d}\left(\mathrm{p}^{-\mathrm{I}}(\mathrm{x})\right)\right)=\mathrm{g}\left(\mathrm{g}^{-\mathrm{I}}\left(\mathrm{a}\left(\mathrm{p}\left(\mathrm{p}^{-\mathrm{I}}(\mathrm{x})\right)\right)\right)\right)=\mathrm{a}(\mathrm{x})$. That is, $\mathrm{H}_{\mathrm{p}, \mathrm{g}}(\mathrm{d})=\mathrm{a}$. Hence $\mathrm{H}_{\mathrm{p}, \mathrm{g}}$ is onto. Lemma. 2

$\mathrm{H}_{\mathrm{p}, \mathrm{g}}$ is a t-homomorphism.

Proof:

Let $c, d \in \mathrm{L}^{\mathrm{X}}$. Then for each $\mathrm{x} \in \mathrm{X}, \mathrm{H}_{\mathrm{p}, \mathrm{g}}(\mathrm{c} \vee \mathrm{d})(\mathrm{x})=\mathrm{g}\left((\mathrm{c} \vee \mathrm{d})\left(\mathrm{p}^{-\mathrm{I}}(\mathrm{x})\right)=\mathrm{g}\left(\mathrm{c}\left(\mathrm{p}^{-\mathrm{I}}(\mathrm{x})\right)\right) \vee \mathrm{g}\left(\mathrm{d}\left(\mathrm{p}^{-}\right.\right.\right.$ $\mathrm{I}(\mathrm{x})))=\mathrm{H}_{\mathrm{p}, \mathrm{g}}(\mathrm{c})(\mathrm{x}) \vee \mathrm{H}_{\mathrm{p}, \mathrm{g}}(\mathrm{d})(\mathrm{x})=\left(\mathrm{H}_{\mathrm{p}, \mathrm{g}}(\mathrm{c}) \vee \mathrm{H}_{\mathrm{p}, \mathrm{g}}(\mathrm{d})\right)(\mathrm{x})$. Thus $\mathrm{H}_{\mathrm{p}, \mathrm{g}}(\mathrm{c} \vee \mathrm{d})=\mathrm{H}_{\mathrm{p}, \mathrm{g}}(\mathrm{c}) \vee \mathrm{H}_{\mathrm{p}, \mathrm{g}}(\mathrm{d})$. Similarly $\mathrm{H}_{\mathrm{p}, \mathrm{g}}(\mathrm{c} \wedge \mathrm{d})=\mathrm{H}_{\mathrm{p}, \mathrm{g}}(\mathrm{c}) \wedge \mathrm{H}_{\mathrm{p}, \mathrm{g}}(\mathrm{d})$. Thus $\mathrm{H}_{\mathrm{p}, \mathrm{g}}$ is a homomorphism. Further, since $\mathrm{g}$ is a $\mathrm{t}-$ homomorphism, for each $\mathrm{x} \in \mathrm{X}, \mathrm{H}_{\mathrm{p}, \mathrm{g}}(\underline{0})(\mathrm{x})=\mathrm{g}\left(\underline{0}\left(\mathrm{p}^{-\mathrm{I}}(\mathrm{x})\right)\right)=\mathrm{g}(\underline{0})=\underline{0}$ and $\mathrm{H}_{\mathrm{p}, \mathrm{g}}(\underline{1})(\mathrm{x})=\mathrm{g}\left(\underline{1}\left(\mathrm{p}^{-\mathrm{I}}(\mathrm{x})\right)\right)=$ $\mathrm{g}(\underline{1})=\underline{1}$. Hence $\mathrm{H}_{\mathrm{p}, \mathrm{g}}(\underline{0})=\underline{0}$ and $\mathrm{H}_{\mathrm{p}, \mathrm{g}}(\underline{1})=\underline{1}$.

Also for $\mathrm{d}_{\mathrm{i}}, \mathrm{i} \in \mathrm{I}$ in $\mathrm{L}^{\mathrm{X}}$ and for all $\mathrm{x} \in \mathrm{X}, \mathrm{H}_{\mathrm{p}, \mathrm{g}}\left(\vee\left(\mathrm{d}_{\mathrm{i}}\right)\right)(\mathrm{x})=\mathrm{g}\left(\left(\vee \mathrm{d}_{\mathrm{i}}\right)\left(\mathrm{p}^{-\mathrm{I}}(\mathrm{x})\right)\right)=\vee \vee \mathrm{g}\left(\mathrm{d}_{\mathrm{i}}\left(\mathrm{p}^{-\mathrm{I}}(\mathrm{x})\right)\right)=\vee$ $\mathrm{H}_{\mathrm{p}, \mathrm{g}}\left(\mathrm{d}_{\mathrm{i}}\right)(\mathrm{x})$. That is, $\mathrm{H}_{\mathrm{p}, \mathrm{g}}\left(\vee\left(\mathrm{d}_{\mathrm{i}}\right)\right)=\vee \mathrm{H}_{\mathrm{p}, \mathrm{g}}\left(\mathrm{d}_{\mathrm{i}}\right)$. Hence $\mathrm{H}_{\mathrm{p}, \mathrm{g}}$ is a t- homomorphism.

Lemma. 3

$\mathrm{H}_{\mathrm{p}, \mathrm{g}}$ is a $\mathrm{t}$ - isomorphism.

Proof:

Follows from the lemma 1 and lemma 2 .

Lemma. 4

If $\delta$ is a fuzzy topology, then the collection $\mathrm{H}_{\mathrm{p}, \mathrm{g}}{ }^{*}(\delta)=\left\{\mathrm{H}_{\mathrm{p}, \mathrm{g}}(\mathrm{a}): \mathrm{a} \in \delta\right\}$ is also a fuzzy topology.

Proof:

(1) $\underline{0} \underset{\in}{\in} \Rightarrow \mathrm{H}_{\mathrm{p}, \mathrm{g}}(\underline{0}) \in \mathrm{H}_{\mathrm{p}, \mathrm{g}}{ }^{*}(\delta) \Rightarrow \underline{0} \in \mathrm{H}_{\mathrm{p}, \mathrm{g}}{ }^{*}(\delta) \quad$ and $\quad \underline{1} \in \delta \Rightarrow \mathrm{H}_{\mathrm{p}, \mathrm{g}}(\underline{1}) \in$ $\mathrm{H}_{\mathrm{p}, \mathrm{g}} *(\delta) \Rightarrow \underline{1} \in \mathrm{H}_{\mathrm{p}, \mathrm{g}} *(\delta)$

(2) Let $\mathrm{f}_{1}, \mathrm{f}_{2} \in \mathrm{H}_{\mathrm{p}, \mathrm{g}} *(\delta)$. Then $\mathrm{f}_{1}=\mathrm{H}_{\mathrm{p}, \mathrm{g}}(\mathrm{a})$ and $\mathrm{f}_{2}=\mathrm{H}_{\mathrm{p}, \mathrm{g}}(\mathrm{b})$ for some $\mathrm{a}, \mathrm{b} \in \delta$. We have $\mathrm{a}, \mathrm{b} \in \delta$ $\Rightarrow \mathrm{a} \wedge \mathrm{b} \in \delta$. Now $\mathrm{f}_{1} \wedge \mathrm{f}_{2}=\mathrm{H}_{\mathrm{p}, \mathrm{g}}(\mathrm{a}) \wedge \mathrm{H}_{\mathrm{p}, \mathrm{g}}(\mathrm{b})=\mathrm{H}_{\mathrm{p}, \mathrm{g}}(\mathrm{a} \wedge \mathrm{b}) \in \mathrm{H}_{\mathrm{p}, \mathrm{g}} *(\delta)$, since $\mathrm{a} \wedge \mathrm{b} \in \delta$.

(3) Let $f_{i}, i \in I$ belongs to $H_{p, g} *(\delta)$. Then $f_{i}=H_{p, g}\left(a_{i}\right)$ for some $a_{i} \in \delta$.

We have $a, b \in \delta \Rightarrow \vee a_{i} \in \delta$. Now $\vee f_{i}=\vee H_{p, g}\left(a_{i}\right)=H_{p, g}\left(\vee a_{i}\right) \in H_{p, g} *(\delta)$, since $\vee a_{i} \in \delta$.

Hence $\mathrm{H}_{\mathrm{p}, \mathrm{g}} *(\delta)$ is a fuzzy topology.

Lemma. 5 
For $\delta \in \operatorname{LFT}(\mathrm{X}, \mathrm{L})$, define $\mathrm{H}_{\mathrm{p}, \mathrm{g}} *(\delta)=\left\{\mathrm{H}_{\mathrm{p}, \mathrm{g}}(\mathrm{a}): \mathrm{a} \in \delta\right\}$. Then $\mathrm{H}_{\mathrm{p}, \mathrm{g}} *(\delta)$ is a fuzzy topology on $\mathrm{X}$ and $\mathrm{H}_{\mathrm{p}, \mathrm{*}}{ }^{*}$ is an automorphism of $\operatorname{LFT}(\mathrm{X}, \mathrm{L})$.

Proof:

From Lemma 4, it follows that $\mathrm{H}_{\mathrm{p}, \mathrm{g}} *(\delta)$ is a fuzzy topology. For $\delta_{1}, \delta_{2} \in \operatorname{LFT}(\mathrm{X}, \mathrm{L})$, let $\mathrm{H}_{\mathrm{p}, \mathrm{g}} *\left(\delta_{1}\right)=$ $\mathrm{H}_{\mathrm{p}, \mathrm{g}} *\left(\delta_{2}\right)$. This implies

$\left\{\mathrm{H}_{\mathrm{p}, \mathrm{g}}(\mathrm{a}): \mathrm{a} \in \delta_{1}\right\}=\left\{\mathrm{H}_{\mathrm{p}, \mathrm{g}}(\mathrm{b}): \mathrm{b} \in \delta_{2}\right\} \Rightarrow\left\{\mathrm{a}: \mathrm{a} \in \delta_{1}\right\}=\left\{\mathrm{b}: \mathrm{b} \in \delta_{2}\right\}$

Therefore $\mathrm{H}_{\mathrm{p}, \mathrm{g}} *$ is one to one.

$$
\Rightarrow \delta_{1}=\delta_{2} \text {. }
$$

Let $\tau \in \operatorname{LFT}(\mathrm{X}, \mathrm{L})$. Consider the collection $\delta=\left\{\mathrm{H}_{\mathrm{p}, \mathrm{g}}{ }^{-\mathrm{I}}(\mathrm{a}): \mathrm{a} \in \tau\right\}$. Then $\delta$ is fuzzy topology and $\mathrm{H}_{\mathrm{p}, \mathrm{g}}{ }^{*}(\delta)=\left\{\mathrm{H}_{\mathrm{p}, \mathrm{g}}{ }^{-\mathrm{I}}(\mathrm{a}): \mathrm{a} \in \tau\right\}=\{\mathrm{a}: \mathrm{a} \in \tau\}=\tau$. Therefore $\mathrm{H}_{\mathrm{p}, \mathrm{g}} *$ is onto.

Further $\delta_{1} \subseteq \delta_{2} \Leftrightarrow\left\{\mathrm{a}: \mathrm{a} \in \delta_{1}\right\} \subseteq\left\{\mathrm{b}: \mathrm{b} \in \delta_{2}\right\} \Leftrightarrow\left\{\mathrm{H}_{\mathrm{p}, \mathrm{g}}(\mathrm{a}): \mathrm{a} \in \delta_{1}\right\} \subseteq\left\{\mathrm{H}_{\mathrm{p}, \mathrm{g}}(\mathrm{b}): \mathrm{b} \in \delta_{2}\right\} \Leftrightarrow \mathrm{H}_{\mathrm{p}, \mathrm{g}} *\left(\delta_{1}\right)$ $\subseteq \mathrm{H}_{\mathrm{p}, \mathrm{s}} *\left(\delta_{2}\right)$.

Hence $\mathrm{H}_{\mathrm{p}, \mathrm{g}} *$ is an automorphism of $\mathrm{LFT}(\mathrm{X}, \mathrm{L})$.

\section{Theorem. 1}

Let $\mathrm{X}$ be any non- empty set and $\mathrm{L}$ be an F- lattice. For a bijection $\mathrm{p}$ on $\mathrm{X}$ and a $\mathrm{t}$-homomorphism $\mathrm{g}$ on $\mathrm{L}$, define $H_{p, g}$ by $H_{p, g}(a)(x)=g\left(a\left(p^{-1}(x)\right)\right) ; a \in L^{X}, x \in X$. Then $H_{p, g}$ is an automorphism on $L^{X}$. Further, for $\delta \in \operatorname{LFT}(X, L)$, let $\mathrm{H}_{\mathrm{p}, \mathrm{g}} *(\delta)=\left\{\mathrm{H}_{\mathrm{p}, \mathrm{g}}(\mathrm{a}): \mathrm{a} \in \delta\right\}$. Then $\mathrm{H}_{\mathrm{p}, \mathrm{g}} *$ is an automorphism of $\operatorname{LFT}(\mathrm{X}, \mathrm{L})$.

Proof:

Follows from lemma 5.

Theorem. 2

Let $\mathrm{X}$ be a finite set and $\mathrm{L}$ be a finite F-lattice. For bijections $\mathrm{p}: \mathrm{X} \rightarrow \mathrm{X}$ and $\mathrm{g}: \mathrm{L} \rightarrow \mathrm{L}$, define $\mathrm{F}_{\mathrm{p}, \mathrm{g}}{ }^{*}$ by $\mathrm{F}_{\mathrm{p}, \mathrm{g}} *(\delta)=\left\{\operatorname{comp}\left(\mathrm{H}_{\mathrm{p}, \mathrm{g}}(\mathrm{a})\right): \mathrm{a} \in \delta\right\}$ where $\operatorname{comp}\left(\mathrm{H}_{\mathrm{p}, \mathrm{g}}(\mathrm{a})\right)$ denotes the pseudo-complement of

Proof: $\mathrm{H}_{\mathrm{p}, \mathrm{g}}(\mathrm{a})$ in $\mathrm{L}^{\mathrm{X}}$. Then $\mathrm{F}_{\mathrm{p}, \mathrm{g}}{ }^{*}$ is an automorphism of $\operatorname{LFT}(\mathrm{X}, \mathrm{L})$.

We have $\underline{0}=\operatorname{comp}(\underline{1})=\operatorname{comp}\left(\mathrm{H}_{\mathrm{p}, \mathrm{g}}(\underline{1)})\right.$ and $\underline{1}=\operatorname{comp}(\underline{0)}=$

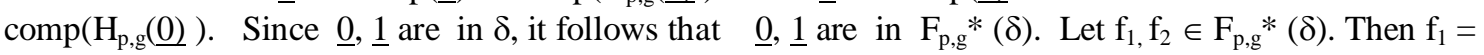
$\operatorname{comp}\left(\mathrm{H}_{\mathrm{p}, \mathrm{g}}(\mathrm{a})\right)$ and $\mathrm{f}_{2}=\operatorname{comp}\left(\mathrm{H}_{\mathrm{p}, \mathrm{g}}(\mathrm{b})\right)$ for some $\mathrm{a}, \mathrm{b} \in \delta$. We have $\mathrm{a}, \mathrm{b} \in \delta \Rightarrow \mathrm{a} \wedge \mathrm{b} \in \delta$. Now,

$\mathrm{f}_{1} \vee \mathrm{f}_{2}=\operatorname{comp}\left(\mathrm{H}_{\mathrm{p}, \mathrm{g}}(\mathrm{a})\right) \vee \operatorname{comp}\left(\mathrm{H}_{\mathrm{p}, \mathrm{g}}(\mathrm{b})\right)$

$=\operatorname{comb}\left\{\mathrm{H}_{\mathrm{p}, \mathrm{g}}(\mathrm{a}) \wedge \mathrm{H}_{\mathrm{p}, \mathrm{g}}(\mathrm{b})\right\}$

$=\operatorname{comb}\left\{\mathrm{H}_{\mathrm{p}, \mathrm{g}}(\mathrm{a} \wedge \mathrm{b})\right\} \in \mathrm{F}_{\mathrm{p}, \mathrm{g}} *(\delta)$

Similarly, $\mathrm{f}_{1} \wedge \mathrm{f}_{2} \in \mathrm{F}_{\mathrm{p}, \mathrm{g}} *(\delta)$. Thus $\mathrm{F}_{\mathrm{p}, \mathrm{g}} *(\delta)$ is a fuzzy topology on $\mathrm{X}$.

For $\delta_{1}, \delta_{2} \in \operatorname{LFT}(\mathrm{X}, \mathrm{L})$, let $\mathrm{F}_{\mathrm{p}, \mathrm{g}} *\left(\delta_{1}\right)=\mathrm{F}_{\mathrm{p}, \mathrm{g}} *\left(\delta_{2}\right)$. This implies,

$\left.\left\{\operatorname{comp}\left(\mathrm{H}_{\mathrm{p}, \mathrm{g}}(\mathrm{a})\right): \mathrm{a} \in \delta_{1}\right\}=\operatorname{comp}\left(\mathrm{H}_{\mathrm{p}, \mathrm{g}}(\mathrm{b})\right): \mathrm{b} \in \delta_{2}\right\} \Rightarrow\left\{\mathrm{a}: \mathrm{a} \in \delta_{1}\right\}=\left\{\mathrm{b}: \mathrm{b} \in \delta_{2}\right\}$

$$
\Rightarrow \delta_{1}=\delta_{2}
$$

Therefore $\mathrm{F}_{\mathrm{p}, \mathrm{g}} *(\delta)$ is one to one.

For $\tau \in \operatorname{LFT}(\mathrm{X}, \mathrm{L})$, consider the collection $\delta=\left\{\mathrm{H}_{\mathrm{p}, \mathrm{g}}{ }^{-\mathrm{I}}(\operatorname{comb}(\mathrm{a})): \mathrm{a} \in \tau\right\}$.

Then $\delta$ is a fuzzy topology on $\mathrm{X}$ and

$$
\begin{aligned}
\mathrm{F}_{\mathrm{p}, \mathrm{g}} *(\delta) & =\left\{\operatorname{comp}\left(\mathrm{H}_{\mathrm{p}, \mathrm{g}}\left(\mathrm{H}_{\mathrm{p}, \mathrm{g}}{ }^{-\mathrm{I}}(\operatorname{comp}(\mathrm{a}))\right)\right): \mathrm{a} \in \tau\right\} \\
& =\{\operatorname{comp}(\operatorname{comp}(\mathrm{a})): \mathrm{a} \in \tau\} \\
& =\{\mathrm{a}: \mathrm{a} \in \tau\} \\
& =\tau
\end{aligned}
$$

Therefore $\mathrm{F}_{\mathrm{p}, \mathrm{*}} *$ is onto. Also,

$$
\begin{array}{rlrl}
\delta_{1} \subseteq \delta_{2} & \Leftrightarrow & & \left\{\mathrm{a}: \mathrm{a} \in \delta_{1}\right\} \subseteq\left\{\mathrm{b}: \mathrm{b} \in \delta_{2}\right\} \\
& \Leftrightarrow & \left\{\mathrm{H}_{\mathrm{p}, \mathrm{g}}(\mathrm{a}): \mathrm{a} \in \delta_{1}\right\} \subseteq\left\{\mathrm{H}_{\mathrm{p}, \mathrm{g}}(\mathrm{b}): \mathrm{b} \in \delta_{2}\right\} \\
& \Leftrightarrow & \left\{\operatorname{comp}\left(\mathrm{H}_{\mathrm{p}, \mathrm{g}}(\mathrm{a})\right): \mathrm{a} \in \delta_{1}\right\} \subseteq\left\{\operatorname{comp}\left(\mathrm{H}_{\mathrm{p}, \mathrm{g}}(\mathrm{b})\right): \mathrm{b} \in \delta_{2}\right\} \\
& \Leftrightarrow & \mathrm{F}_{\mathrm{p}, \mathrm{g}} *\left(\delta_{1}\right) \subseteq \mathrm{F}_{\mathrm{p}, \mathrm{g}} *\left(\delta_{2}\right)
\end{array}
$$

Hence $\mathrm{F}_{\mathrm{p}, \mathrm{g}} *(\delta)$ is an automorphism of LFT(X,L).

\section{Example. 1}

Let $X=\{a, b\}, L=\{0,1 / 2,1\}$. Then the lattice $L^{X}=\left\{a^{0} b^{0}, a^{1} b^{1}, a^{1 / 2} b^{1 / 2}, a^{0} b^{1 / 2}, a^{0} b^{1}, a^{1 / 2} b^{0}, a^{1 / 2} b^{1}, a^{1} b^{0}\right.$, $\left.a^{1} b^{1 / 2}\right\}$ where $a^{i} b^{j} ; i, j=0,1 / 2,1$ is the map $a \rightarrow i$ and $b \rightarrow j$. Let $S(X)$ denotes the group of bijections on $X$ and $A(L)$ denotes the group of automorphisms of $L$. Then $S(X)=\left\{p_{1}, p_{2}\right\}$ where $p_{1}$ is the identity map on $X$ and $p_{2}$ is the map on $X$ which sends $a \rightarrow b$ and $b \rightarrow a$. $A(L)$ consists only one member $g$ which is the identity map on $\mathrm{L}$. Thus by Theorem 1 and Theorem $2, \mathrm{H}_{\mathrm{p} 1, \mathrm{~g}}{ }^{*}, \mathrm{H}_{\mathrm{p} 2, \mathrm{~g}}{ }^{*}, \mathrm{~F}_{\mathrm{p} 1, \mathrm{~g}}{ }^{*}$ and $\mathrm{F}_{\mathrm{p} 2, \mathrm{~g}}{ }^{*}$ are automorphisms of the lattice LFT(X,L).

Example. 2

Let $X=\{x, y\}, L=\{0, a, b, 1\}$ where $a$ and $b$ are not comparable. Then the lattice $L^{X}=\left\{x^{0} y^{0}, x^{a} y^{a}\right.$, $\left.x^{b} y^{b}, x^{0} y^{1}, x^{0} y^{a}, x^{0} y^{b}, x^{1} y^{0}, x^{1} y^{a}, x^{1} y^{b}, x^{a} y^{b}, x^{b} y^{a}, x^{a} y^{1}, x^{b} y^{1}, x^{a} y^{0}, x^{b} y^{0}, x^{1} y^{1}\right\}$ where $x^{i} y^{j} ; i, j=0, a, b, 1$ is the 
map on $X$ which sends $x \rightarrow i$ and $y \rightarrow j$. Here, $S(X)=\left\{p_{1}, p_{2}\right\}$ where $p_{1}$ is the identity map on $X$ and $p_{2}$ is the map which sends $\mathrm{x} \rightarrow \mathrm{y}$ and $\mathrm{y} \rightarrow \mathrm{x}$. $\mathrm{A}(\mathrm{L})=\left\{\mathrm{g}_{1}, \mathrm{~g}_{2}\right\}$ where $\mathrm{g}_{1}$ is the identity map on $\mathrm{L}$ and $\mathrm{g}_{2}$ is the map which sends $0 \rightarrow 0, a \rightarrow b, b \rightarrow a, 1 \rightarrow 1$.

Thus by Theorem 1 and Theorem $2, \mathrm{H}_{\mathrm{p} 1, \mathrm{~g} 1} *, \mathrm{H}_{\mathrm{p} 1, \mathrm{~g} 2} *, \mathrm{H}_{\mathrm{p} 2, \mathrm{~g} 1} *, \mathrm{H}_{\mathrm{p} 2, \mathrm{~g} 2} *, \mathrm{~F}_{\mathrm{p} 1, \mathrm{~g} 1} *, \mathrm{~F}_{\mathrm{p} 1, \mathrm{~g} 2} *, \mathrm{~F}_{\mathrm{p} 2, \mathrm{~g} 1} *$ and $\mathrm{F}_{\mathrm{p} 2, \mathrm{~g} 2} *$ are automorphisms of $\operatorname{LFT}(\mathrm{X}, \mathrm{L})$.

Remark. 3

When $\mathrm{L}=\{0,1\}, \operatorname{LFT}(\mathrm{X}, \mathrm{L})$ coincides with $\mathrm{LT}(\mathrm{X}), \mathrm{H}_{\mathrm{p}, \mathrm{g}}{ }^{*}$ coincides with $\mathrm{A}_{\mathrm{p}}$ and $\mathrm{F}_{\mathrm{p}, \mathrm{g}}{ }^{*}$ coincides with $B_{p}$ where $A_{p}$ and $B_{p}$ are as defined in the beginning of this paper. Note that we are identifying the subsets of $\mathrm{X}$ as characteristic functions.

\section{Acknowledgements}

The author wishes to thanks Dr. P.T. Ramachandran, Department of Mathematics, University of Calicut for his valuable guidance during the preparation of this paper.

\section{References}

[1] S.Babusunar, Some Lattice Problems in Fuzzy Set Theory and Fuzzy Topology, Thesis for Ph.D. Degree, Cochin University of Science and Technology, 1989.

[2] Juris Hartmanis, On the Lattice of Topologies, Cand. J . Math.\} \{ \bf 10\} (1958), 547-553.

[3] Birkhoff, Lattice Theory, Amer. Math. Soc. Colloq. Publ. Vol.25, Amer. Math.Soc. Pro vidence, 1967.

[4] H.J.Zimmerman, Fuzzy Set Theory and its Applications, Second Edition. Kluwer Academic Publishers, Boston, 1991.

[5] Liu, Ying-Ming \& Mao-Kang, Luo, Fuzzy Topology, Advances in Fuzzy Systems-Applications and Theory, Vol.9, World Scientific Pub. Co. Pvt. Ltd. 1997. 